\title{
In-situ synthesis of TiC/Ti-6Al-4V-ELI composite by laser
}

\author{
P Ramasobane ${ }^{1 *}$, P M Mashinini' ${ }^{1}$ B Masina ${ }^{1,2}$
}

\author{
1 Department of Mechanical \& Industrial Engineering Technology, University of Johannesburg, Johannesburg, South Africa \\ ${ }^{2}$ National Laser Centre, Council for Scientific and Industrial Research, Meiring Naudé Road, Brummeria, Pretoria 0001, South Africa \\ Email: pushetso@icloud.com
}

\begin{abstract}
Titanium-based alloys are reported to offer up to $50 \%$ strength to weight ratio. These lands titanium-based alloys as a preferred material over steel and nickel-base super-alloys, where strength and stiffness are required. Regardless titanium-based alloys are prone to losing strength and stiffness at elevated temperature applications such as jet engines. This prompted a need for titanium matrix to be braced with a material with superior properties, such as ceramic. In-situ synthesis with laser metal deposition (LMD) of Ti-6Al-4V-ELI braced with discontinuous particulates of $\mathrm{TiC}$ resulted in improved hardness and microstructure. It is reported that an increase in the feed rate of TiC during the LMD process directly increases the hardness of the TiC/Ti-6Al-4V-ELI composite and refine the grain size of Ti-6Al4V-ELI. Various fabrication methods and properties of Ti-6Al-4V are well documented in the literature. This paper focuses on the effect of $\mathrm{TiC}$ on the microstructure and hardness of Ti-6Al-4V-ELI.
\end{abstract}

Keywords: TiC/Ti-6Al-4V-ELI, Direct metal deposition, Metal matrix composite, Micro-hardness

\section{Introduction}

A gradual layer-by-layer manufacturing approach is referred to as additive manufacturing (AM); this contrasts traditional, subtractive manufacturing methods (Emmelmann, et al., 2013). AM technology uses powder or wire as a feedstock specifically melted by a focused heat source and polarised in subsequent cooling to form a part (Carroll, et al., 2015). AM has enticed concentration over the past decades because of its inherent benefits, such as unparalleled design freedom and short lead times (Kranz, et al., 2015). In the current age, it has become viable to reliably produce dense parts with the selected additive manufacturing process and several materials, including steel, aluminium ( $\mathrm{Al}$ ), and titanium (Ti) (Murr, et al., 2012).

The relation between the process, microstructure, and properties of AM technology still need to be explored. To argue the effectiveness of AM, the microstructure and mechanical properties of the material are studied and equated with those of a conventionally manufactured. Ti alloys have low hardness values, poor resistance to wear, and oxidation at elevated temperatures (Polmear, 1981).

Ti-6Al-4V alloy is the workhorse titanium alloy in the aerospace industry because of its excellent corrosion resistance and toughness (Tabrizi, et al., 2015) (Lu, et al., 2012). Though, the low surface hardness and wear resistance of Ti-6Al-4V restricts its application (Xing, et al., 2011). The introduction of ceramic particulate reinforced titanium matrix composite (TMC) is confirmed to be an efficient way to enhance the hardness and tensile properties of Ti6Al-4V (Xing, et al., 2013). TiC is studied as a favorite particulate reinforcement for the Ti-6Al-4V matrix composite predicted on its high thermal stability, high hardness, and harmony with titanium alloy (Qi, et al., 2012) (Wang, et al., 2014).

Mahamood and Akinlabi (Mahamood \& Akinlabi, 2015) operated the LMD process to simulate the functionally graded TiC/Ti-6Al-
$4 \mathrm{~V}$. They reported that the enhanced process parameters were critical to acquiring acceptable performance. In the research by Wang et al. (Wang, et al., 2007), the TiC/Ti-6Al-4V composite was fabricated by LMD by applying the TiC powder and Ti-6Al-4V wire, which were synchronized into the melt pool. The resultant microstructure was acquired by keeping the Ti-6Al-4V wire constant and altering the feed rate of TiC powder. Specific unmelted TiC particles in the matrix were observed when the volume fraction of $\mathrm{TiC}$ was high. Though, the primary $\mathrm{TiC}$ and secondary $\mathrm{TiC}$ appeared when the $\mathrm{TiC}$ volume fraction was low. Reinforced TiC particles enhanced the tribological attributes of the Ti-6Al-4V matrix.

Ti-6Al-4V alloy possesses two crystal structures alpha $(\alpha)$ and beta $(\beta)$. The $\alpha$-phase is hexagonal close-packed, and the $\beta$-phase is body-centered cubic, providing the foundation for developing a wide range of $\mathrm{Ti}$ alloys with rare characteristics. This two-phase combination provides Ti-6Al-4V with competitive mechanical properties up to $450^{\circ} \mathrm{C}$. Modification of Ti-6Al-4V-ELI with TiC is expected to improve selected mechanical properties. The low hardness and poor wear resistance of Ti-6Al-4V limit its utilization as engineering tribological components ( $\mathrm{Li}$, et al., 2015). According to (Wang, et al., 2021), a typically employed approach to enhance the wear performance of Ti alloys is by infusing Ni to get hard and wear-resistant metallic phases. Fabrication reinforced by ceramics is helpful to enhance the tribological attributes of Ti$6 \mathrm{Al}-4 \mathrm{~V}$ elements. Considering the interfaces between Ti-6Al-4V elements and ceramic reinforced facings, attributes like thermal expansion coefficient have an abrupt modification (Li, et al., 2019). As a result, of this unanticipated modification in properties, failures such as cracking and spalling are more probable to occur at the interfaces (Pettersson, et al., 2005).

This study will produce a TiC/Ti-6Al-4V-ELI metal matrix composite by LMD processes using Ti-6Al-4V-ELI and TiC powders. The formation mechanism of primary and eutectic $\mathrm{TiC}$ 


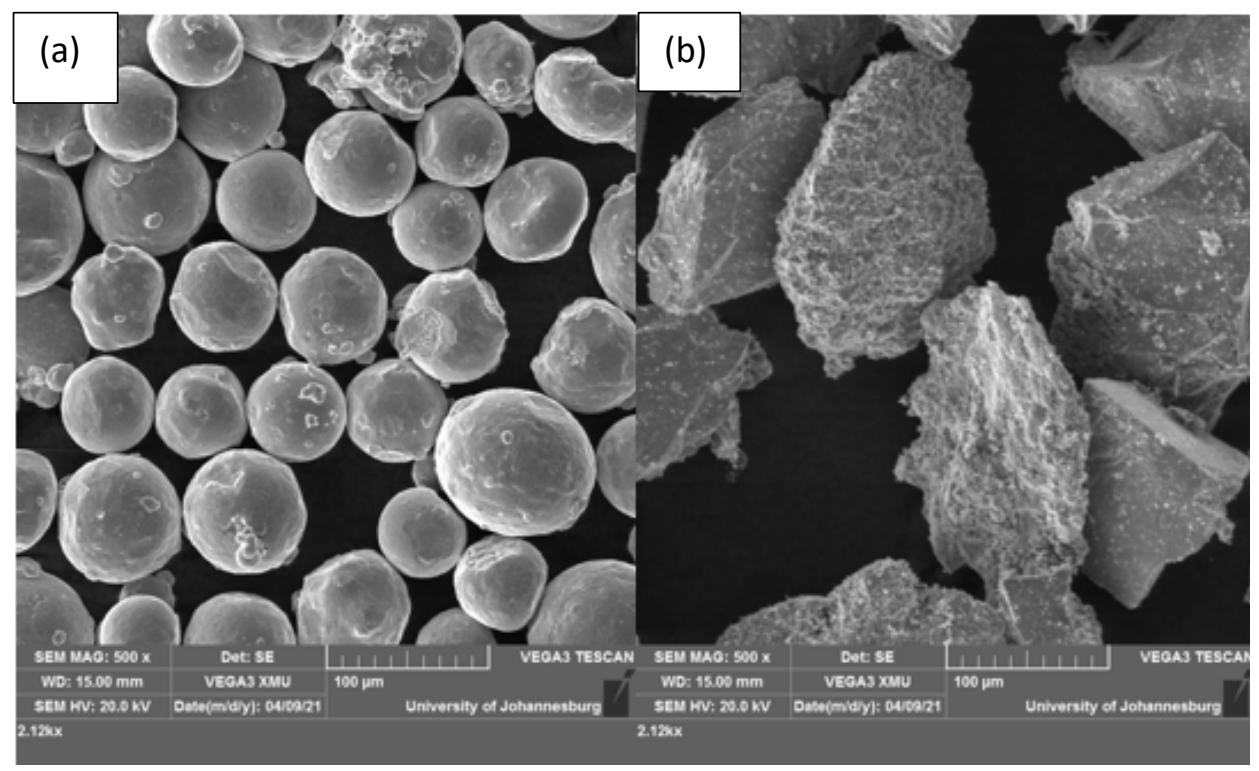

Figure 1: SEM morphology of (a) Ti-6Al-4V-ELI and (b) TiC

will be studied together with the microstructure and microhardness of the TiC/Ti-6Al-4V-ELI metal matrix composite. In addition, the influence of primary and eutectic $\mathrm{TiC}$ on the microhardness of $\mathrm{TiC} /$ Ti-6Al-4V-ELI will be discussed.

\section{Material characterization and methods}

Ti-6Al-4V plate with the following dimensions $72 \mathrm{~mm} \times 72 \mathrm{~mm}$ x $5 \mathrm{~mm}$ was used as a substrate. The materials used in this study were titanium carbide ( $\mathrm{TiC}$ ) powder with an average particle size ranging from 129 to $206 \mu \mathrm{m}$ and Ti-6Al-4V-ELI powder with an average particle distribution of 182 to $241 \mu \mathrm{m}$ with a purity of $99 \%$, the morphology of the powders is shown in Figure 1 below. A $3 \mathrm{~kW}$ IPG multi-mode Ytterbum fiber laser (1073 nm) was used to manufacture the TiC/Ti-6Al-4V-ELI MMC clads onto Ti-6Al-4V plate. Figure 2 indicates a schematic diagram of the LMD experimental setup that was used in this study. Two hoppers were utilized for both powders. During the laser metal deposition process, as described in the Figure. 2, the coaxial nozzle moved 193 $\mathrm{mm}$ distance paralleling to the substrate for single-layer deposition. The powder feed rate was controlled individually by adjusting the rotational speed of every powder feeder. The rotational speed for the Ti-6Al-4V-ELI powder hopper changed from $2.5 \mathrm{rpm}$ to 7.5 rpm, while that of the TiC powder hopper changed from $0 \mathrm{rpm}$, $0.1 \mathrm{rpm}$, and $0.3 \mathrm{rpm}$. The argon gas was used as the carrier and shielding gas, the flow of which was maintained at $1.5 \mathrm{1} / \mathrm{min}$ and in the range of $15 \mathrm{l} / \mathrm{min}$, respectively. The laser scanning speed, laser power, and laser spot size were maintained at $0.5 \mathrm{~m} / \mathrm{min}$, $1500 \mathrm{~W}$, and $2 \mathrm{~mm}$ all the time during the laser metal deposition process. It is common knowledge that the melting of $\mathrm{TiC}$ is higher than the $\mathrm{Ti}$ (Ya, et al., 2015), thus requiring more energy input to melt when the volume fraction of $\mathrm{TiC}$ is increased. Since the $\mathrm{TiC}$ particles were the composite reinforcements, the complete melting of the TiC powders was not required in this experiment. Thus, the laser power, laser spot size, and scanning speed were kept constant when the volume fraction of $\mathrm{TiC}$ increased. Several TiC/Ti6A14V metal matrix composites (MMC) clad samples were manufactured while varying each powder's feeder rate, respectively. The $\mathrm{TiC} /$

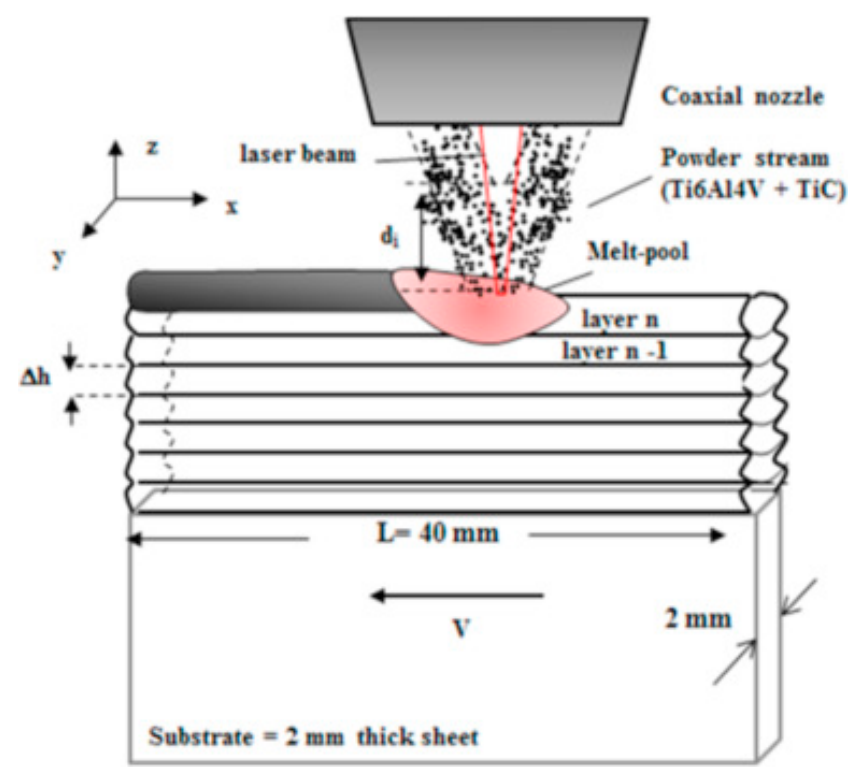

Figure 2: Schematic diagram of the LMD experimental setup (Pouzet, et al., 2016)

Ti-6Al-4V-ELI MMC clad samples were cut perpendicular to the deposition direction for microstructural and microhardness analysis. The samples then were ground, polished, and etched using Kroll's reagent. The TiC/Ti-6Al-4V-ELI MMC clad samples' microstructure was analyzed by GX 51 Olympus optical microscope and VEGA3 TESCAN Scanning Electron Microscopy (SEM). The microhardness of the TiC/Ti6Al4V-ELI MMC clad samples was measured using a Zwick Vickers hardness indenter with a load of $300 \mathrm{~g}$ and a dwell time of 15 seconds.

\section{Results and discussion}

\section{Microstructure of TiC/Ti6Al4V-ELI}

Figure 3(a) shows the microstructure of the as-built Ti-6Al-4VELI; it is observed that black particles are distributed evenly across the microstructure. It was further observed that the grain growth is irregular toward the top of the clad and regular at the interface. In the middle of the clad, a mixture of irregular columnar grains and 

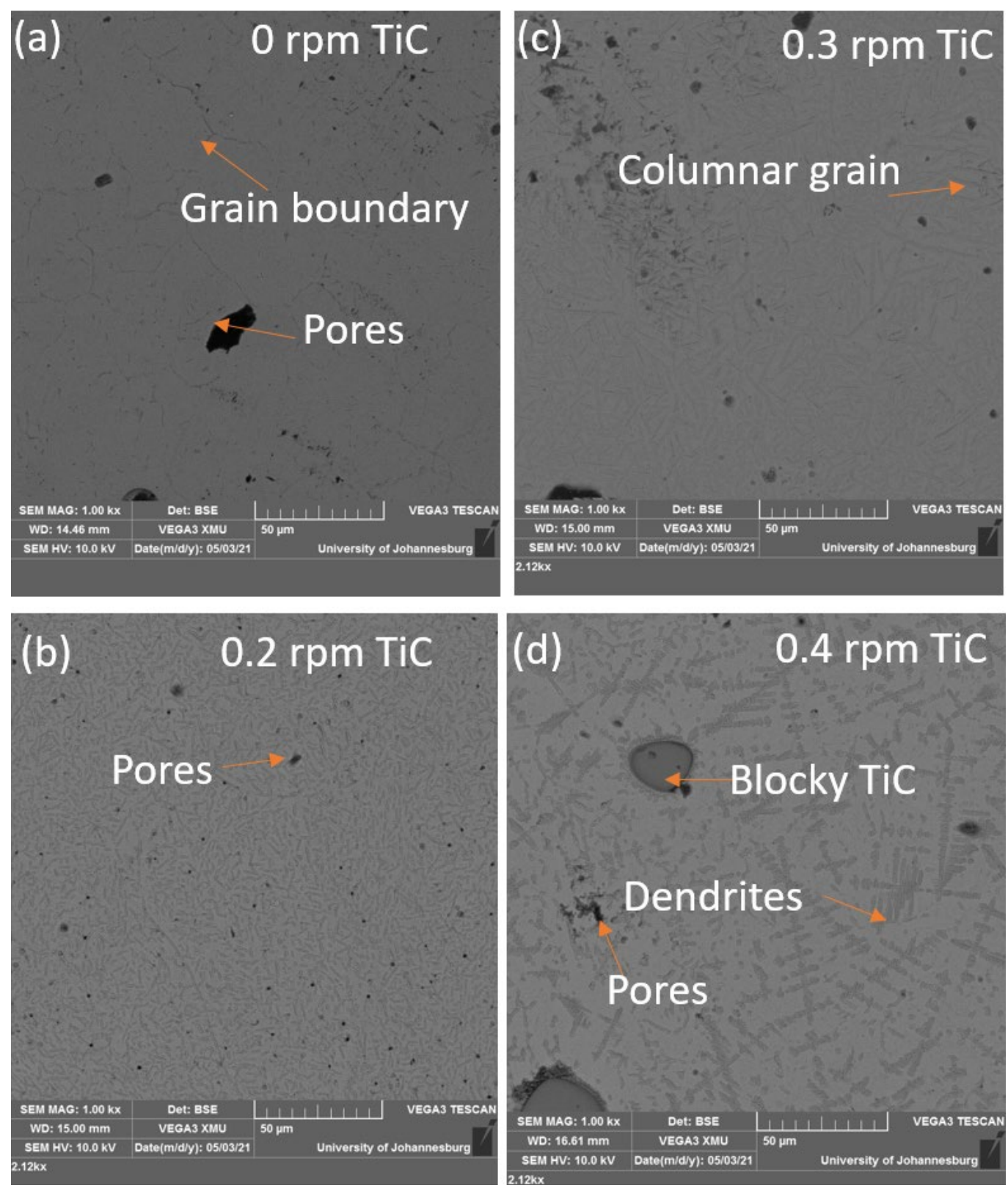

Figure 3: Microstructure evolution of Ti-6Al-4V-ELI with increasing TiC content (a) $0 \mathrm{rpm} \mathrm{TiC,} \mathrm{(b)} 0.2 \mathrm{rpm} \mathrm{TiC}$, (c) $0.3 \mathrm{rpm} \mathrm{TiC}$ and (d) $0.4 \mathrm{rpm} \mathrm{TiC}$

equiaxed grains was observed in the middle of the built. The Ti6Al-4V-ELI microstructure evolution starts with the solidification of the beta $(\beta)$ phase referred to as the prior $\beta$-Ti phase, which transforms to acicular $\left(\alpha\right.$ ') phase during cooling below $920^{\circ} \mathrm{C}$, which appears like a needle-like light-colored in a prior $\beta$ phase. There is a presence of defects on the as-built clad that has been confirmed with SEM as pore.

Figure 3(b) shows the TiC/Ti-6Al-4V-ELI fabricated with the feed rate of $0.2 \mathrm{rpm} \mathrm{TiC}$ and 5rpm Ti-6Al-4V-ELI; in this Figure, it is observed that the grain boundary is clearly defined. The $\alpha^{\prime}$ is in the prior beta matrix. The granular grain shape is observed along with chain-shaped and granular TiC morphology as described in Figure 4 by $\mathrm{Li}$ et al. Figure 3(c) shows the TiC/Ti-6Al-4V-ELI fabricated with the feed rate of $0.3 \mathrm{rpm}$ TiC and 5rpm Ti-6Al-4V-ELI, below indicates that as the feed rate of $\mathrm{TiC}$ increases, more secondary phase particles are precipitating in addition to the previously detected pores, primary eutectic $\mathrm{TiC}$, which are observed in the microstructure. The structure also shows that there are un-melted (blocky) TiC and nucleation of primary dendrites. Figure 3(d) shows the TiC/Ti-6Al-4V-ELI fabricated with the feed rate of $0.4 \mathrm{rpm} \mathrm{TiC}$ and $5 \mathrm{rpm}$ Ti-6Al-4V-ELI, shows a supersaturated dendritic structure in a prior $\beta$-Ti matrix, with some blocky TiC, still observed. It is observed that Figure 4(d) is saturated with dendrites as compared to Figures 3(b) and 3(c). It is also observed in Figure 4 that as the feed rate of $\mathrm{TiC}$ increases, the grain boundary of the prior $\beta$-Ti is not clearly defined as in Figures, 3(a) \& (b), where the volume fraction of $\mathrm{TiC}$ is relatively low.

Figure 4 indicates the effect of $\mathrm{TiC}$ on the microstructure of the Ti-6Al-4V-ELI alloy. It is indicated that below 5\% vol. fraction of $\mathrm{TiC}$, the following morphology of TiC can be observed, blocky, eutectic, primary $\mathrm{TiC}$ phases. Above 5\% - 50\% vol. fraction $\mathrm{TiC}$ blocky and dendritic phases are dominant, with patches of eutectic and primary TiC phase. Observed microstructure corresponds very well with literature ( $\mathrm{Li}$, et al., 2017) . In a study by $\mathrm{Li}$ et al. 


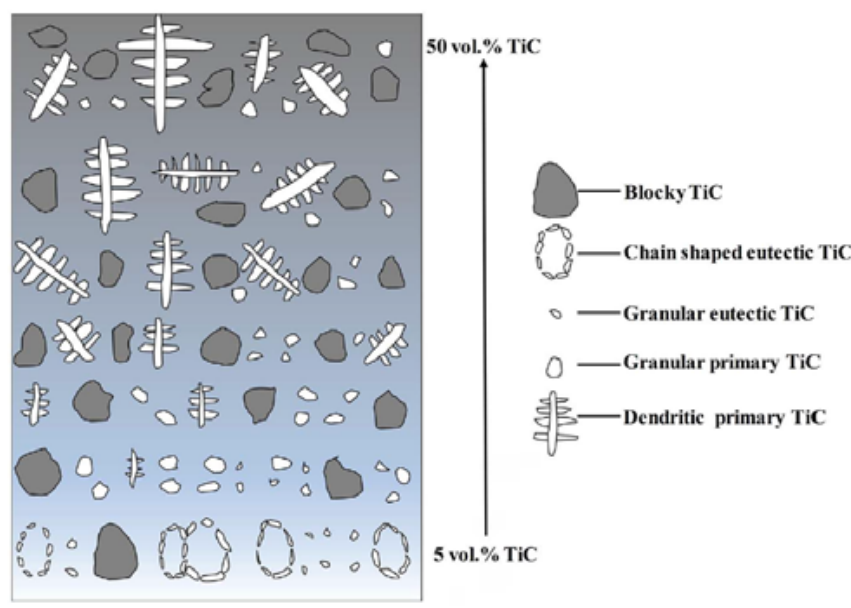

Figure 4: Schematic microstructural diagram of TiC/Ti6Al4V composite produced by LMD (Li, et al., 2017)

(Li, et al., 2017), it is reported that the addition of TiC to the Ti$6 \mathrm{Al}-4 \mathrm{~V}-\mathrm{ELI}$ will lead to grain refinement and second phase solid solution strengthening of $\alpha$-Ti and $\beta$-Ti grains in the matrix. It is observed that an increased amount of TiC volume fraction leads to the evolution of the Ti-6Al-4V-ELI microstructure with the TiC morphology described in Figure 4. Below 5\% volume fraction is the embedded structure of granular eutectic TiC and primary eutectic TiC, chain-shaped morphology. The percentage volume fraction of $5 \%$ to $50 \%$ of the morphology embedded in the Ti-6Al$4 \mathrm{~V}$-ELI matrix composite is expected to be the dendrite primary $\mathrm{TiC}$ and blocky TiC, with minimum distribution eutectic $\mathrm{TiC}$ in the matrix of Ti-6Al-4V-ELI.

Figure 5 below shows the effect of change in the feed rate of Ti-6Al-4V-ELI on the microstructure evolution of the TiC/Ti6Al-4V-ELI matrix composite. (a) Indicate the Ti-6Al-4V-ELI feed rate of $7.5 \mathrm{rpm}$; under this parameter, defects are observed in the microstructure, second phase particles that appear black and embedded in the prior $\beta$ matrix are followed, by the granular eutectic. (b) Shows the micrograph of the feed rate of $5 \mathrm{rpm}$ of Ti-6Al-4V-ELI; in this microstructure, dendrite nucleation in the prior $\beta$ matrix is observed together with the granular eutectic TiC in the matrix. (c) Shows the microstructure of TiC/Ti-6Al-4V-
ELI composite with a feed of $2.5 \mathrm{rpm}$ for Ti-6Al-4-ELI; on this microstructure, it is observed that it is supersaturated with primary dendritic TiC, embedded as a second phase precipitate in the microstructure, black particles can still be observed in the matrix.

\section{Hardness Profile}

A micro-hardness test with Zoell Vickers micro-hardness, conducted on the deposited TiC/Ti-6Al-4V-ELI clad, is reported in Figure 6. It was observed that the substrate, which is Ti-6Al-4V has an average micro-hardness of $300 \mathrm{HV}_{0.3}$, with $\pm 50 \mathrm{HV}_{0.3}$. It is further observed that the deposited layer of Ti-6Al-4V-ELI has a micro-hardness of $300 \mathrm{HV}_{0.3}$ with $\pm 50 \mathrm{HV}_{0.3}$. The deposited layer of Ti-6Al-4V-ELI yielded similar hardness reading with the Ti-6Al$4 \mathrm{~V}$ substrate. It is observed that the addition of $\mathrm{TiC}$ to Ti-6Al-4VELI has a direct effect on the hardness property of TiC/Ti-6Al-4VELI, as shown in Figure 6, significant impact on the microstructure as it was observed that the micro-hardness value increased from an average of $352 \mathrm{HV}_{0.3}$ to an average of $427 \mathrm{HV}_{0.3}$.

Figure 7 below shows the hardness profile of the built component with a constant feed rate of $0.3 \mathrm{rpm}$ for $\mathrm{TiC}$ and varying feed rate for Ti-6Al-4V-ELI records the micro-hardness of $340 \mathrm{HV}_{0.3}$, with $\pm 50 \mathrm{HV}_{0.3}$ in the substrate and from the heat-affected zones (HAZ) to the clad micro-hardness ranges from $330 \mathrm{HV}_{0.3}$ to about 480 $\mathrm{HV}_{0.3}$. This reading in hardness indicates that varying the feed rate of Ti-6Al-4V-ELI does affect the hardness of the composite. It is evident that the hardness reading increases steeply in the HAZ, in the interface zone, and transitions to the clad; the hardness reading seems to level up with a minimum variation in hardness reading as indicated in Figure 7. The hardness reading for $2.5 \mathrm{rpm}, 5 \mathrm{rpm}$, and $7.5 \mathrm{rpm}$ shows an increase between the depth of 200 to $400 \mu \mathrm{m}$, while 2.5 shows a drop from $470 \mathrm{HV}_{0.3}$ to in $\mathrm{HAZ}$ to $460 \mathrm{HV}_{0.3}$ in the interface zone, in it shows a fluctuation between $455 \mathrm{HV}_{0.3}$ to $485 \mathrm{HV}_{0.3}$. The $5 \mathrm{rpm}$ shows a decrease from $480 \mathrm{HV}_{0.3}$ in the HAZ/ interface to $460 \mathrm{HV}_{0.3}$ and a linear hardness reading in the clad zone. The $7.5 \mathrm{rpm}$ indicates an increase in hardness from substrate/ HAZ to a depth of $800 \mu \mathrm{m}$, then it drops. This increase in hardness is due to the grain refinement of Ti-6Al-4V-ELI with TiC. A sharp drop in hardness at a depth of $8001000 \mu \mathrm{m}$ in $7.5 \mathrm{rpm}$ Ti-6Al-4VELI is due to the lack of TiC particles near the surface of the clad.
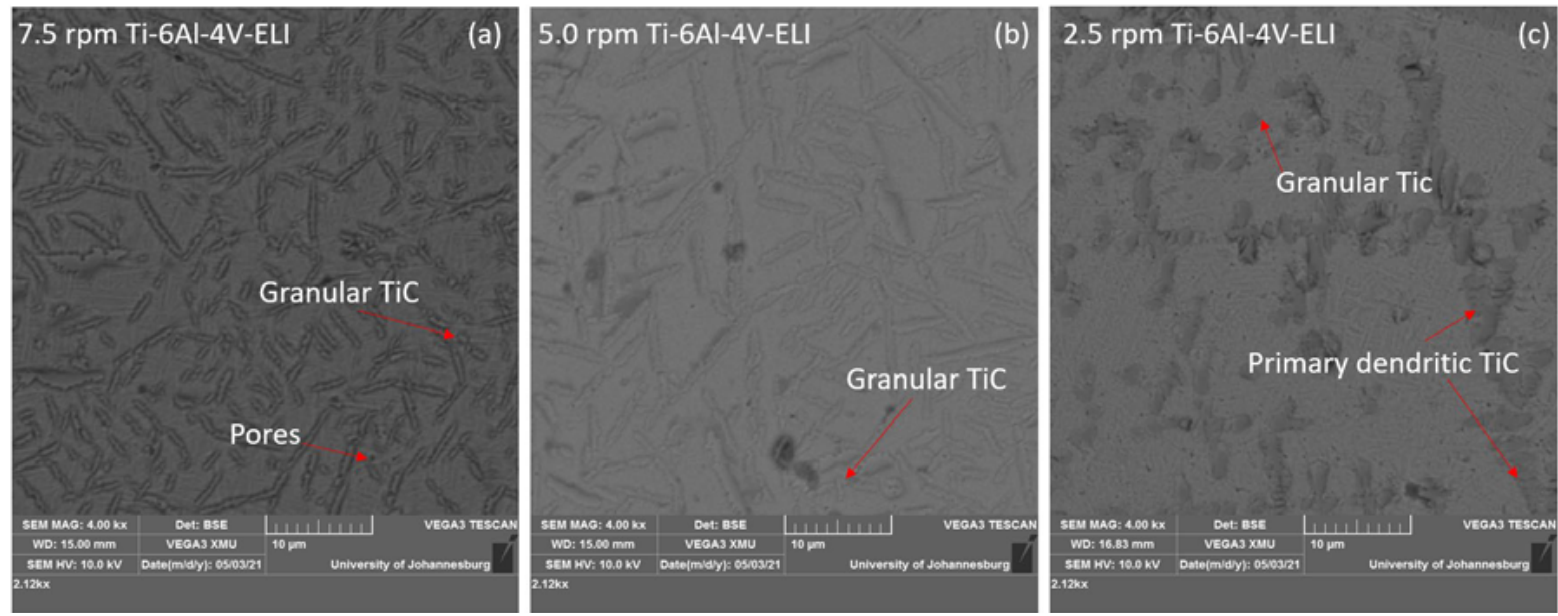

Figure 5: Microstructure evolution of TiC/Ti-6Al-4V-ELI with decreasing Ti-6Al-4V-ELI feed rate, (a) $7.5 \mathrm{rpm}$ Ti-6Al-4V-ELI, (b) 5.0 rpm Ti-6Al-4V-ELI, and (c) 2.5 rpm Ti-6Al-4V-ELI 


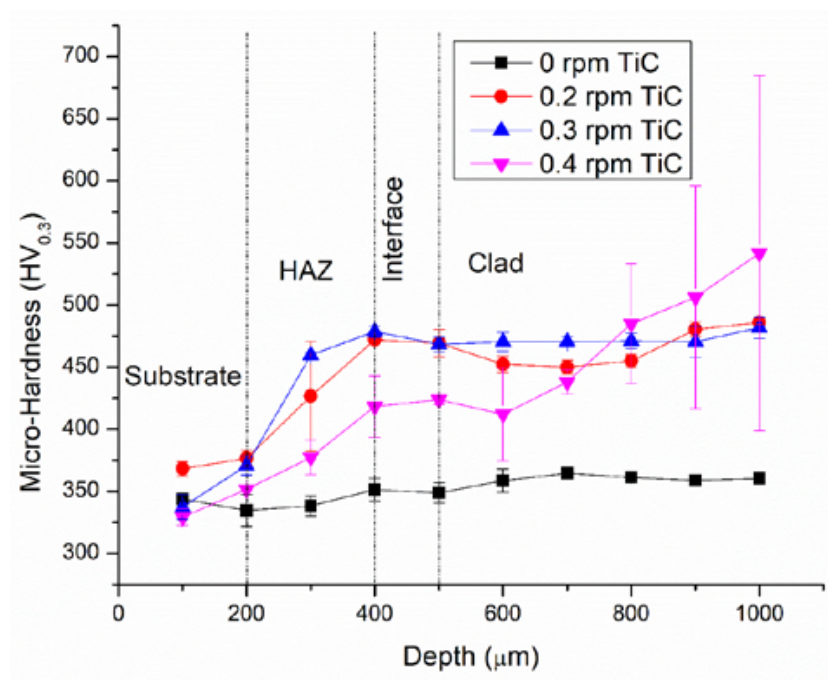

Figure 6: Vickers microhardness profile of TiC/Ti6-Al-4V-ELI

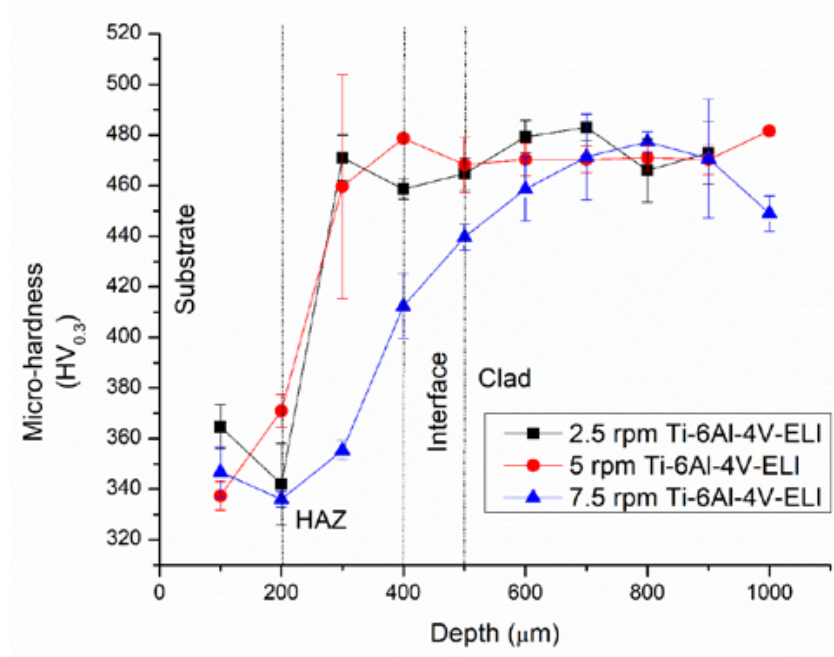

Figure 7: Vickers microhardness $\left(\mathrm{HV}_{0.3}\right)$, with varying Ti-6Al4V-ELI feed rate

\section{Conclusion}

This study manufactured TiC/Ti6Al4V-ELI composite with the LMD technique through an in-situ reaction of Ti-6Al-4V-ELI and $\mathrm{TiC}$ powders. The effect of $\mathrm{TiC}$ volume on microstructural formation and hardness was evident. The following conclusions were made:

- LMD of Ti-6Al-4V-ELI and TiC result in chain-shaped eutectic, granular eutectic, and primary eutectic.

- Below the $10 \%$ volume fraction of $\mathrm{TiC}$, the following morphologies dominate, chain-shaped eutectic, granular eutectic, and primary eutectic TiC. Where volume fraction exceeds, $10 \%$ primary dendritic $\mathrm{TiC}$ is observed

- The formation of dendrites increases with an increasing volume of $\mathrm{TiC}$.

- Hardness remarkably increases with an increasing volume of TiC.

\section{Acknowledgments}

The authors acknowledge the following individuals and or organization/s:

1. The Department of Science and Innovation (DSI), through the Collaborative Program in Additive Manufacturing (CPAM), for funding of this study.

2. The National Laser Center at the Council for Scientific and Industrial Research (NLC-CSIR) uses its facilities.

3. Mr. Paul Lekoadi for producing samples.

\section{References}

1. Carroll, B. E., Palmer, T. A. \& Besse, A. M., 2015. Anisotropic tensile behavior of Ti-6Al-4V components fabricated with directed energy deposition additive manufacturing. Acta Materials, Volume 87, pp 309-320.

2. Emmelmann, C., Kranz, J., Herzog, D. \& Wycisk., E., 2013. Laser Additive Manufacturing of Metals: in Laser Technology in Biomimetics. Heidelberg: Springer.

3. Kranz, J., Herzog, D. \& Emmelmann, C., 2015. Design guidelines for laser additive manufacturing of light structures in Ti-6Al-4V. Journal of Laser Applications.

4. Li, L., Wang, J., Lin, P. \& Liu, H., 2017. Microstructural and mechanical properties of functionally graded $\mathrm{TiC} / \mathrm{Ti} 6 \mathrm{~A} 14 \mathrm{~V}$ composite fabricated by laser melting deposition. Ceramics International, Volume 43, pp. 16638-16651.

5. Li, N. et al., 2019. Microstructure, formation mechanism and property characterization of $\mathrm{Ti}+\mathrm{SiC}$ laser cladded coatings on Ti6Al4V alloy. Materials Characterization, Volume 148, pp. 43-51.

6. Li, X. et al., 2015. Effects of sliding velocity on tribo-oxides and wear behaviour of Ti-6Al-4V alloy. Tribo International, Volume 91, pp. 228-234.

7. Lu, Y. et al., 2012. Microstructure evolution of sub-critical annealed laser deposited Ti-6Al-4V alloy. Material Design, Volume 37, pp. 56-63.

8. Mahamood, R. M. \& Akinlabi, E. T., 2015. Laser metal deposition of functionally graded TiC/Ti-6Al-4V. Materials \& Design, Volume 84, pp. 402-410.

9. Murr, L. E. et al., 2012. Metal fabrication by additive manufacturing using laser and electron beam melting technologies. Science \& Technology, 28(1), pp. 1-14.

10. Pettersson, A., Magnusson, P., Lundberg, P. \& Nygren, M., 2005. Titanium-titanium diboride composite as part of a gradient armour mater. International Journal of Impact Engineering, 32(1-4), pp. 387-399.

11. Polmear, J. J., 1981. Titanium alloys in Light Alloys. London, UK: Edward Arnold.

12. Pouzet, S. et al., 2016. Additive layer manufacturing of titanium matrix composites using the direct metal deposition laser process. Materials Science \& Engineering, Issue A, pp. 677171-181.

13. Qi, J. Q., Wang, H. H., Zhou, C. M. \& Wei, Z. J., 2012. Influence of matrix characteristics on tensile properties of in-situ synthesized $\mathrm{TiC}$ TA15 composite. Material Science Engineering, Volume A 553, pp. 59-66.

14. Tabrizi, S. G., Sajadi, S. A., Babakhani, A. \& Lu, W. J. 2015. Influence of spark plasma sintering and subsequent hot rolling on microstructure and flexural behavior of in-situ $\mathrm{TiB}$ and $\mathrm{TiC}$ reinforced Ti6A14V composite. Material Science Engineering, Volume A 624, pp. 271-278.

15. Wang, D. Y. et al., 2014. Fabrication and characterization of TiB2/ $\mathrm{TiC}$ composites. International Journal of Refractory Metals Hard Materials, Volume 45, pp. 95-101.

16. Wang, F., Mei, J. \& Wu, X. H., 2007. Compositionally graded Ti6Al4V + TiC made by direct laser fabrication using powder and wire. Materials \& Design, Volume 28, pp. 2040-2046.

17. Wang, J. et al., 2021. Microstructure and hardness variation of additively manufactured Ti-Ni-C functionally graded composites. Journal of Alloys and Compounds, Volume 865.

18. Xing, J. Q., Tian, S. G., Bao, X. Y. \& Chen, L. Q., 2011. Creep properties and effect factors of hot continuous rolled Ti-6Al-4V alloy. Material Science Engineering, Volume A 526, pp. 452-458.

19. Xing, Y. Z., Jiang, C. P. \& Hao, J. M., 2013. Time dependence of microstructure and hardness in plasma carbonized Ti-6Al-4V alloys. Vaccum, 95(9), pp. 1-17.

20. Ya, B. et al., 2015. Microstructure and mechanical properties of in situ casting TiC/Ti-6Al-4V composites through adding multi-walled carbon nanotubes. Journal of Alloys and Compounds, Volume 637, pp. 456-460. 